Published by LPMP Imperium

Journal homepage: https:/ / ejournal.imperiuminstitute.org/ index.php/JMSAB

\title{
Pengaruh Fitur dan Harga Produk Terhadap Keputusan Pembelian Telepon Pintar
}

\section{Ermalina}

Manajemen, STIE Ahmad Dahlan

Paper type

Research paper

\begin{abstract}
The purpose of this research is to understand the price and product feature towards purchase decision smartphone V. This research is a quantitative research by using the SPSS Statistic 25 with population unknown and 120 respondents of sample which use smartphone $\mathrm{V}$ in South jakarta who have bought smartphone V. The sample design in this study uses non probability sampling method and purposive sampling techniques. The result of this research data technical used multiple linear regression analysis and it shows significant effect both partially and simultaneously between price and product feature toward purchase decision
\end{abstract}

\begin{abstract}
Abstrak
Tujuan dari penelitian ini adalah untuk mengetahui harga dan fitur produk terhadap keputusan pembelian smartphone V. Penelitian ini adalah penelitian kuantitatif dengan menggunakan SPSS Statistic 25 dengan populasi tidak diketahui dan 120 responden sampel yang menggunakan smartphone $\mathrm{V}$ di Jakarta Selatan yang memiliki membeli smartphone V. Desain sampel dalam penelitian ini menggunakan metode non probability sampling dan teknik purposive sampling. Hasil data teknis penelitian ini menggunakan analisis regresi linier berganda dan menunjukkan pengaruh yang signifikan baik secara parsial dan simultan antara harga dan fitur produk terhadap keputusan pembelian.
\end{abstract}

*Email korespondensi: ermalina1962@gmail.com

Pedoman Sitasi: Ermalina, E (2020). Pengaruh Harga Dan Fitur Produk Terhadap Keputusan Pembelian Telepon Pintar. Jurnal Manajemen Strategi dan Aplikasi Bisnis, 3(1), 11 - 20

Keywords: Price, product feature, purchase decision.

Received: 6 Dec 2019

Revised: 14 Jan 2020

Accepted: 20 Jan 2020

Online: 22 Jan 2020

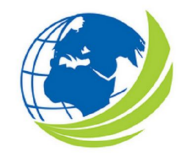

Jurnal Manajemen Strategi dan Aplikasi Bisnis, Vol 3, No.1, Januari 2020, pp. 11 - 20 eISSN 2655-237X 


\section{PENDAHULUAN}

Industri telekomunikasi merupakan salah satu industri yang paling pesat di Indonesia, sektor telekomunikasi telah menunjukan pertumbuhan sampai awal tahun 2018, pertumbuhan tersebut didukung oleh adanya kemajuan teknologi internet, Namun industri telekomunikasi yang menjadi tulang punggung layanan internet. Banyak konsumen di Indonesia menikmatinya berbagai kebutuhan, mulai dari perangkat internet, perangkat komunikasi sederhana, perangkat komunikasi modern hingga smartphone (Tekno.Kompas, 2019). Oleh karena itu, setiap perusahaan yang beroperasi di bidang telekomunikasi berusaha memberikan sesuatu yang terbaik kepada konsumen untuk mempertahankan kelangsungan hidup bisnisnya.

Indonesia merupakan salah satu pasar terbesar penjualan smartphone di Asia, tingkat permintaan terhadap produk smartphone yang tinggi membuat persaingan pasar yang sangat kompetitif. Canalys, salah satu perusahaan riset konsumen global, menyebut Indonesia sebagai pasar Smartphone paling progresif di Asia Pasifik dengan permintaan ponsel pada 2018 meningkat sebesar 17,1\% dibandingkan tahun 2017. Selain itu, tahun 2018, Indonesia memiliki rekor dengan pengiriman perangkat tertinggi mencapai 38 juta. Berdasarkan laporan kuartal keempat 2018, total pengiriman smartphone di Indonesia mencapai 9,5 juta unit, dengan pertumbuhan sebesar 8,6\% dari tahun ke tahun (YoY).

Ketatnya persaingan antar produsen telpon pintar menyebabkan banyak perusahaan berupaya untuk memahami pasar lebih baik. Mohd Azam Osman et al (2012) menjelaskan bahwa teknologi smartphone mengubah perilaku masyarakat khususnya dewasa muda namun survei yang telah dilakukan masih relative terbatas. Ada kekurangan pemahaman tentang perilaku dan preferensi konsumen terhadap penggunaan smartphone terutama untuk dewasa muda. Berdasarkan hasil survey yang dilakukan oleh Ericsson Consumer Lab pada tahun 2013, 57 persen mahasiswa menggunakan smartphone, 60 persen merasa kecanduan telepon, sementara 75 persen dari mereka tidur di sebelah telepon mereka, 88 persen mengirim sms di kelas, 97 persen menggunakannya untuk social media, dan 40 persen menggunakan smartphone untuk belajar sebelum ujian. Selain itu, industri ponsel selalu menunjukkan perubahan atau perkembangan yang drastis dan luar biasa di pasar telekomunikasi. Model baru smartphone diluncurkan ke pasar dari waktu ke waktu untuk mendapatkan keunggulan kompetitif di pasar. Evolusi pasar smartphone telah mempengaruhi pengguna terutama generasi muda dalam hal motif dan pilihan yang mendasari proses keputusan pembelian smartphone (Rahim et al., 2016).

Berbagai studi yang dilakukan untuk mengidentifikasi preferensi pemilihan smartphone telah dilakukan (Rahim et al., 2016; DjatmiNoak \& Pradanab, 2016; Bues et al., 2017). Promosi harga adalah pendorong nilai yang paling tidak penting, sedangkan lokasi menerima iklan seluler adalah pendorong niat pembelian yang paling kuat. (Bues et al., 2017). Penelitian lain menunjukkan bahwa fitur produk, nama merek dan pengaruh sosial memiliki hubungan yang signifikan kecuali satu variabel, pengorbanan produk yang tidak memiliki hubungan yang signifikan dengan niat pembelian (Rahim et al., 2016). Fitur produk dan harga juga dinyatakan sebagai preditor utama dari keputusan pembelian (DjatmiNoak \& Pradanab, 2016; Irfan \& Rachmawati, 2018). Variabel fitur memiliki kemampuan terlemah untuk mempengaruhi keputusan pembelian (Amron, 2018). Uraian di atas menunjukkan bahwa faktor yang mempengaruhi keputusan pembelitian terutama pada produk smartphone masih berbeda-beda sehingga topic ini masih menarik untuk diteliti ulang.

Penelitian ini bertujuan untuk mengetahui pengaruh harga produk terhadap keputusan pembelian produk smartphone Telepon Pintar V. Penelitian ini dapat membantu produsen untuk memahami pentingnya fitur produk dan harga terhadap niat beli smartphone di kalangan mahasiswa di Indonesia. 


\section{KAJIAN PUSTAKA}

Keputusan pembelian

Niat pembelian merupakan rencana awak untuk membeli barang atau jasa tertentu di masa depan. Meski demikian, niat beli tidak selalu dilaksanakan karena masih tergantung pada kemampuan individu untuk melakukan (Qun et al., 2012). Menurut Blackwell et al. (2001), apa yang terlintas dalam benak pelanggan menandakan niat untuk beli oleh mereka. Para peneliti menyatakan bahwa konsumen akan melalui proses mengenali produk untuk dibeli, kemudian mereka akan menemukan informasi tentang produk, mengevaluasi, membeli dan umpan balik. Oleh karena itu, mereka akan membeli produk setelah melakukan penelitian terlebih dahulu sehingga mereka akan membeli produk yang tepat yang memenuhi kebutuhan dan keinginan mereka.

Menurut Tjiptono (2014:21) keputusan pembelian adalah sebuah proses dimana konsumen mengenal masalahnya, mencari informasi mengenai produk atau merek tertentu dan mengevaluasi seberapa baik masing-masing alternatif tersebut dapat memecahkan masalahnya, yang kemudian mengarah kepada keputusan pembelian. Sementara menurut Sumarwan dalam Sari dan Yuniati (2016), Keputusan pembeliaan adalah kegiatan dimana yang dilakukan oleh konsumen untuk membeli dan mengkonsumsi suatu produk atau jasa dalam rangka untuk memenuhi kebutuhan dan keinginannya.

\section{Fitur produk dan keputusan pembelian}

Dalam pembuatan produk perlu adanya hal yang istimewa, unik dan yang berbeda dari produk lain, fitur produk atau spesifikasi dalam produk tentunya dapat mewakili keunggulan dari produk itu sendiri, dari fitur produk atau spesifikasi dari produk itu sendiri konsumen dapat membedakan dari produk satu dengan produk yang lain. Fitur produk memiliki peran kunci dalam membuat produk yang baik dan sering diasosiasikan dengan kemanfaatan atau fungsionalitas dari suatu produk. Kotler dan Keller (2012:8) menyatakan bahwa Fitur adalah salah satu dari delapan dimensi kualitas produk. Fitur dapat dikatakan sebagai aspek sekunder dari suatu produk. Fitur identik dengan sesuatu yang unik, khas, dan istimewa yang tidak dimiliki oleh produk lainnya, sehingga menjadi alat persaingan untuk membedakan produk perusahaan terhadap produk sejenis dari pesaing. Sama halnya dengan Kotler dan Armstrong terjemahan Bob Sabran (2014:254) yang menyatakan bahwa fitur adalah alat untuk bersaing yang membedakan produk suatu perusahaan dengan perusahaan lainnya. Fitur produk identik dengan sifat dan sesuatu yang unik, khas dan istimewa yang tidak dimiliki oleh produk lainnya. Biasanya karakteristik yang melekat dalam suatu produk merupakan hasil pengembangan dan penyempurnaan secara terus-menerus. Sebuah produk dapat ditawarkan dengan beraneka macam fitur. Perusahaan dapat menciptakan model dengan tingkat yang lebih tinggi dengan menambah beberapa fitur produk tersebut. Berdasarkan pengertian yang telah dikemukakan oleh para ahli maka dapat dinyatakan bahwa konsumen selalu ingin mendapatkan produk yang berkualitas sesuai dengan harga yang dibayar, walaupun terdapat sebagian masyarakat yang berpendapat bahwa, produk yang mahal adalah produk yang berkualitas. Jika hal itu dapat dilaksanakan oleh perusahaan, maka perusahaan tersebut akan dapat tetap memuaskan para konsumen dan dapat menambah jumlah konsumen.

Fitur adalah sarana untuk membedakan produk perusahaan dari para pesaingnya. Menjadi produsen pertama yang memperkenalkan fitur bernilai baru adalah salah satu cara paling efektif untuk bersaing (Vila dan Ampuero, 2007; Boyce et al., 2008). Fitur adalah karakteristik atau kemampuan yang mungkin atau mungkin tidak dimiliki oleh produk. Produk serupa dapat dilihat secara berbeda oleh konsumen dari perbandingan fitur di antara mereka, yaitu, perbandingan kelengkapan fitur, kecanggihan fitur, atau eksklusivitas dalam suatu produk daripada yang lain. Saat ini, ada banyak fitur teknologi tinggi dari smartphone di pasar. Dengan demikian, orang yang berbeda akan memilih fitur smartphone yang berbeda yang dapat memenuhi kebutuhan dan keinginan mereka. Menurut Oulasvirta et al. (2011), smartphone saat ini sedang ditampilkan dengan 
konektivitas nirkabel, browser web built-in, instalasi aplikasi, program penuh, sistem manajemen file, presentasi dan penangkapan multimedia, tampian layar resolusi tinggi, kapasitas penyimpanan dan lokasi serta sensor gerakan. Berdasarkan penelitian sebelumnya, ada lima karakteristik desain ponsel yang disukai oleh konsumen seperti kamera, layar warna, panggilan dengan suara aktif, penelusuran internet dan konektivitas nirkabel (Ling et al., 2006, dalam Rahim et al., 2016).

Banyak peneliti sebelumnya melakukan penelitian mereka tentang efek fitur pada keputusan pembelian konsumen dengan mengaitkannya. dari berbagai aspek. Misalnya Baruk dan Iwanica (2015) meneliti hubungan antara fitur dan keputusan pembelian yang melibatkan 100 responden di Polandia. Penelitian menemukan bahwa ada hubungan antara fitur dan keputusan pembelian. Khan et al. (2012) juga menemukan hal yang sama bahwa fitur tersebut dapat mempengaruhi keputusan pembelian secara positif. Beberapa penelitian memberikan kesimpulan bahwa responden usia muda dan mahasiswa memilih untuk membeli ponsel karena penampilan fisiknya, ukuran dan organisasi menu. Fitur produk dapat didefinisikan sebagai atribut dari suatu produk yang dapat memuaskan preferensi konsumen (Kotler \& Armstrong, 2009). Menurut Lay-Yee et al (2013), perangkat keras adalah permukaan perangkat yang dapat disentuh secara fisik seperti tubuh smartphone, ukuran, berat, warna juga desain. Sementara itu, perangkat lunak meliputi program komputer, prosedur dan dokumentasi. Selain itu, platform operasi, penyimpanan atau aplikasi juga dapat dikategorikan sebagai perangkat lunak. Ada beberapa jenis operasi perangkat lunak seperti iOS, Android, Windows, Blackberry RIM, dan Symbia. Hardware dan perangkat lunak dapat dikategorikan sebagai fitur produk. Berdasarkan penelitian sebelumnya yang dilakukan oleh Russell (2012), konsumen di Malaysia kebanyakan lebih suka Android terdiri dari 41\%, diikuti oleh iOS dengan 18\%, RIM Blackberry dan Windows mencatat sama dengan 6\%. Para pengguna di negara lain seperti Singapura, Australia, Selandia Baru, Thailand dan Vietnam kebanyakan menggunakan sistem operasi Android. Penelitian yang dilakukan oleh Lay-Yee et al (2013) menemukan bahwa 31\% pengguna lebih suka perangkat lunak dibandingkan dengan perangkat keras hanya 17,6\%. Ini menunjukkan konsumen akan lebih melihat pada perangkat lunak daripada perangkat keras dalam membeli smartphone. Sejalan dengan itu, studi di Indonesia yang dilakukan oleh Rumate (2014) menemukan bahwa keputusan pembelian dipengaruhi oleh kualitas produk. Meskipun memiliki pengaruh terlemah dibandingkan harga dan citra merek, fitur produk smartphone secara signifikan mempengaruhi keputusan pembelian (Amron, 2018). Berdasarkan uraian tersebut, hipotesis yang diajukan adalah:

H1: fitur produk berpengaruh signifikan terhadap keputusan pembelian

\section{Harga dan keputusan pembelian}

Menurut Daryanto (2013:62) mendefinisikan harga jumlah uang yang ditagihkan untuk suatu produk atau sejumlah nilai yang dipertukarkan konsumen untuk manfaat memiliki atau menggunakan produk. Menurut Kotler dan Amstrong (2014:312), harga adalah sejumlah uang yang dibebankan atas suatu barang atau jasa atau jumlah dari nilai uang yang ditukar konsumen atas manfaat manfaat karena memiliki atau menggunakan produk atau jasa tersebut. Sama halnya dengan Alma (2013:169) mendefinisikan Harga (price) sebagai nilai suatu barang yang dinyatakan dengan uang. Harga memiliki dua peranan utama dalam proses pengambilan keputusan para pembeli, yaitu peranan alokasi dan peranan informasi. Dari Beberapa definisi tersebut dapat disimpulkan bahwa harga adalah unsur penting dalam sebuah perusahaan dimana dengan adanya harga maka perusahaan akan mendapatkan income bagi keberlangsungan perusahaan, dan harga juga merupakan suatu nilai yang melekat pada suatu barang dan nilai tersebut dinyatakan dengan alat tukar.

Harga adalah jumlah uang yang ingin ditukar oleh konsumen untuk suatu layanan atau produk (Kotler dan Armstrong, 2014). Harga merupakan faktor penting yang memengaruhi pembeli untuk membuat keputusan pembelian. Harga adalah jumlah uang yang dibebankan pada suatu produk atau 
layanan, atau jumlah nilai yang dipertukarkan oleh konsumen untuk manfaat memiliki atau menggunakan produk atau layanan. Harga adalah nilai barang yang dituliskan oleh uang atau jumlah semua nilai yang ditukar oleh konsumen untuk kepentingan memiliki atau menggunakan produk atau layanan (Nguyen dan Meng, 2016). Harga tidak hanya tergantung pada kebijakan perusahaan, tetapi mempertimbangkan banyak hal termasuk sudut pandang konsumen (Kwon et al., 2008). Harga dikatakan mahal, murah, atau adil berbeda dari satu orang ke orang lain karena itu tergantung pada latar belakang masing-masing individu. Agar berhasil dalam mempromosikan layanan atau produk, setiap perusahaan harus menetapkan harganya dengan tepat. Harga adalah satu-satunya elemen pemasaran yang memberikan penghasilan bagi perusahaan (Amron, 2018). Selain itu, harga adalah elemen yang fleksibel dalam pemasaran, itu berarti harga dapat berubah dengan cepat (Kwon et al., 2008).

Banyak penelitian telah dilakukan yang mengeksplorasi hubungan antara variabel harga dengan keputusan pembelian. Beneke et al. (2013) meneliti peran harga pada keputusan pembelian dengan melakukan penelitian dengan metode survei di Afrika Selatan. Hasilnya menemukan pengaruh positif dan signifikan antara harga dan keputusan pembelian. Studi lain dilakukan oleh Nguyen dan Meng (2016) yang juga mendukung penelitian sebelumnya bahwa ada hubungan positif antara harga dan keputusan pembelian konsumen. Djatmiko dan Pradanab (2016) menemukan bahwa keputusan pembelian tidak hanya ditentukan oleh produk, melainkan juga harga. Amron (2018) memberikan kesimpulan bahwa empat variabel independen yaitu citra merek, desain, fitur, dan harga menunjukkan kemampuan mereka untuk mempengaruhi keputusan pembelian konsumen dalam arah yang positif. Berdasarkan penjelasan tersebut maka hipotesis yang diajukan adalah:

H2: harga berpengaruh signifikan terhadap keputusan pembelian

\section{METODE}

\section{Desain Penelitian}

Penelitian ini merupakan penelitian yang bersifat kuantitatif, yaitu menggunakan angka-angka untuk ditarik kesimpulannya (Hendryadi, Tricahyadinata, \& Zannati, 2019). Kuesioner tertutup digunakan untuk mengumpulkan data primer dari masing-masing responden. Kuesioner didistribusikan di antara individu yang tinggal di Jakarta. Sebanyak 120 orang responden ditentukan secara purposive. Berdasarkan gender, 37\% responden adalah laki-laki, sedangkan persentase responden perempuan adalah 63\%. Mayoritas responden termasuk dalam kelompok usia dari 18-25 tahun yang tercatat $64 \%$, diikuti oleh $22 \%$ untuk tingkat usia $26-30$ dan hanya $12 \%$ responden dengan usia di atas 30 tahun.

\section{Pengukuran}

Pengukuran tiga variabel diadaptasi dari penelitian Shabrin et al. (2017). Keputusan pembelian terdiri dari 8 item pernyataan dengan contoh "Saya memiliki rencana untuk membeli smartphone dalam waktu dekat" dan "Saya mencari informasi tentang smartphone secara teratur". Harga diukur dengan 5 item pernyataan seperti "Saya lebih suka membeli ponsel pintar dengan harga tinggi" dan "Saya lebih suka membeli ponsel pintar dengan harga lebih murah". Fitur diukur dengan 6 item pernyataan seperti: "Saya lebih suka smartphone yang dilengkapi dengan kamera depan dan belakang dengan megapixel" dan "Saya lebih suka smartphone yang dilengkapi dengan sistem suara yang bagus". Seluruh variabel diukur menggunakan Skala Likert 5 poin dengan 1 (sangat tidak setuju) hingga 5 (sangat setuju).

Tes reliabilitas digunakan untuk mengidentifikasi konsistensi keseluruhan item yang digunakan untuk menentukan skala. Cronbach's alpha adalah teknik yang banyak digunakan untuk mengukur keandalan. Nilai alpha lebih besar dari 0,7 dianggap memenuhi syarat (Hair et al., 2010). Studi ini memberikan bukti alpha Cronbach lebih besar dari 0,70 untuk seluruh variabel. Sedangkan uji validitas item menggunakan analisis faktor dengan cut-off value pada loading factor sebesar 0.50 . 
Hasil analisis menunjukkan bahwa seluruh item yang digunakan sudah memenuhi syarat validitas (loading factor >.50).

Tabel 1. Uji Reliabilitas dan Validitas

\begin{tabular}{llcc}
\hline Konstrak & item & $\begin{array}{c}\text { Loading } \\
\text { factor }\end{array}$ & $\begin{array}{l}\text { Cronbach } \\
\text { Alpha }\end{array}$ \\
\hline Keputusan Pembelian & Y1 & 0.68 & 0.834 \\
& Y2 & 0.78 & \\
& Y3 & 0.85 & \\
& Y4 & 0.82 & \\
& Y5 & 0.72 & \\
& Y6 & 0.65 & \\
Y7 & 0.85 & \\
\hline Fitur & Y8 & 0.87 & \\
& Fitur1 & 0.75 & 0.792 \\
& fitur2 & 0.84 & \\
& Fitur3 & 0.68 & \\
& Fitur4 & 0.75 & \\
& Fitur5 & 0.78 & \\
& Fitur6 & 0.82 & \\
\hline Harga & Price1 & 0.87 & 0.892 \\
& price2 & 0.84 & \\
& Price3 & 0.82 & \\
& Price4 & 0.79 & \\
& Price5 & 0.81 & \\
\hline
\end{tabular}

Sumber: data lapangan, diolah (2019)

\section{HASIL DAN PEMBAHASAN}

\section{Hasil analisis}

Analisis deskriptif pada data yang ditampilkan pada Tabel 2 memperlihatkan nilai rata-rata, standar deviasi dan korelasi antar variabel.

Tabel 2. Analisis deskriptif dan korelasi antar variabel

\begin{tabular}{lrrrrrr}
\hline & Mean & std.dev & KP & FIT & HRG \\
\hline KP & 3.72 & 1.25 & 1 & & \\
FIT & 3.22 & 2.58 & $.533^{*} \&$ & 1 & \\
HRG & 3.88 & 1.37 & $.644^{* *}$ & $.233^{* *}$ & 1 \\
\hline
\end{tabular}

Sumber: data lapangan, diolah (2019)

Hasil analisis menemukan bukti bahwa ada korelasi antara fitur produk, harga, dan keputusan pembelian. Seluruh korelasi signifikan di level 5\%. Korelasi antara variabel fitur dan harga adalah sebesar 0.233 yang mengindikasikan bahwa model regresi terbebas dari masalah multikolinieritas.

Penelitian ini menggunakan regresi berganda bertahap (stepwise regression) untuk menghitung nilai variabel. Regresi bertahap adalah metode untuk memilih subset efek yang berguna dalam model regresi. Metode ini secara analitik menambahkan variabel yang paling signifikan atau menghapus variabel yang paling tidak signifikan selama setiap langkah. Ini membantu untuk secara 
interaktif menemukan prediktor mana yang tampaknya cocok. Dengan menggunakan regresi bertahap, penelitian ini menentukan bahwa fitur produk dan harga adalah prediktor terbaik dari keputusan untuk membeli smartphone. Tabel 2 menggambarkan ringkasan model dan menunjukkan bahwa nilai adj. $\mathrm{R}^{2}$ adalah 0,534 untuk model yang mencakup harga dan fitur produk sebagai variabel independen. Tabel 3 menunjukkan bahwa dua variabel independen secara statistik memprediksi variabel dependen, F (4.852), p <005. Statistik uji Fes menunjukkan bahwa ada hubungan linier antara variabel dalam model ini dan bahwa model regresi cocok untuk data (good fit).

Tabel 3. Ringkasan Hasil Regresi

\begin{tabular}{lllll}
\hline Variabel & Koefisien & t-value & Sig & Kesimpulan \\
\hline Konstanta & 8.751 & - & & \\
Harga & 0,432 & 3.495 & 0.00 & Signifikan \\
Fitur & 0.680 & 8.375 & 0.00 & Signifikan \\
Adj. R & 0,534 & & & \\
F-Statistic & 4.852 & & & \\
\hline
\end{tabular}

Sumber: data lapangan, diolah (2019)

Hasil uji $\mathrm{T}$ adalah nilai sig. untuk pengaruh harga terhadap keputusan pembelian adalah sebesar $0.000<0.05$ dan nilai T hitung $3.495>1.96$. Selanjutnya, nilai sig. untuk pengaruh harga terhadap keputusan pembelian adalah sebesar $0.000<0.05$ dan nilai T Hitung $8.375>1.96$, sehingga dapat disimpulkan $\mathrm{H} 2$ diterima.

\section{Pembahasan}

Tujuan dari penelitian ini adalah untuk menyelidiki faktor-faktor yang mempengaruhi niat pembelian smartphone di kalangan mahasiswa di Jakarta. Secara khusus, penelitian ini menguji hubungan antara fitur dan harga pada niat beli smartphone. Data dikumpulkan dari 120 mahasiswa strata 1 dan strata 2 di salah satu perguruan tinggi swasta di Jakarta. Dua hipotesis disajikan untuk menguji hubungan antara variabel independen; fitur dan harga dan niat beli smartphone sebagai dependen. Temuan menunjukkan bahwa dua hipotesis didukung.

Penelitian ini mendukung temuan sebelumnya seperti Baruk dan Iwanica (2015) yang membuktikan hubungan antara fitur dan keputusan. Khan et al. (2012) juga menemukan hal yang sama bahwa fitur tersebut dapat mempengaruhi keputusan pembelian secara positif. Lay-Yee et al (2013) menemukan bahwa 31\% pengguna lebih suka perangkat lunak dibandingkan dengan perangkat keras hanya 17,6\%. Ini menunjukkan konsumen akan lebih melihat pada perangkat lunak daripada perangkat keras dalam membeli smartphone. Sejalan dengan itu, studi di Indonesia yang dilakukan oleh Rumate (2014) menemukan bahwa keputusan pembelian dipengaruhi oleh kualitas produk. Meskipun memiliki pengaruh terlemah dibandingkan harga dan citra merek, fitur produk smartphone secara signifikan mempengaruhi keputusan pembelian (Amron, 2018). Dapat dinyatakan bahwa semakin baik fitur smartphone, maka akan semakin tinggi pula tingkat ketertarikan konsumen untuk membeli.

Berikutnya, hasil penelitian juga menemukan bahwa harga memiliki pengaruh signifikan terhadap keputusan pembelian. Penelitian ini sejalan dengan penelitian yang dilaksanakan oleh Nguyen dan Meng (2016) dan Beneke et al. (2013) mengenai pengaruh harga terhadap keputusan pembelian. Serta mengkonfirmasi temuan Djatmiko dan Pradanab (2016) menemukan bahwa keputusan pembelian tidak hanya ditentukan oleh produk, melainkan juga harga. Amron (2018) memberikan kesimpulan bahwa empat variabel independen yaitu citra merek, desain, fitur, dan harga menunjukkan kemampuan mereka untuk mempengaruhi keputusan pembelian konsumen dalam arah yang positif. Dapat dinyatakan bahwa kebijakan penetapan harga sebuah smartphone akan memiliki dampak pada keputusan pembelian responden. 


\section{KESIMPULAN}

Ponsel cerdas adalah alat yang berguna untuk komunikasi dan menjadi semakin penting bagi kebutuhan manusia secara umum. Hasil penelitian ini menemukan bukti korelasi yang signifikan secara statistik antara keputusan untuk membeli smartphone berdasarkan fitur produk dan harga. Studi ini khususnya penting bagi produsen dan distributor ponsel pintar di Jakarta secara umum, dan pada pembeli usia muda secara khusus. Bukti penelitian menunjukkan bahwa produsen dan distributor perlu menetapkan fokus pada fitur produk mereka agar dapat bersaing dengan produk lainnya. Fitur produk yang perlu mendapatkan perhatian berdasarkan nilai koefisien bobot faktor adalah kamera yang memiliki resolusi tinggi dan kapasitas penyimpanan memori. Sedangkan untuk harga, kesesuaian antara harga dan kualitas perlu mendapatkan perhatian perusahaan dengan cara melakukan perbandingan harga dengan produk sejenis yang memiliki kualifikasi setara.

\section{Keterbatasan}

Penelitian ini memiliki keterbatasan antara lain: pertama, ukuran sampel kecil yaitu 120 responden yang ditentukan dengan teknik purposive sehingga memiliki keterbatasan generalisasi. Sampel yang lebih besar dan lebih representatif dapat menghasilkan hasil yang lebih kuat. Kedua, penelitian ini dilakukan di satu lokasi dan hanya menggunakan dua variabel independen untuk memahami keputusan pembelian smartphone, mungkin ada faktor lain yang mempengaruhi keputusan pembelian ponsel cerdas seperti citra merek, faktor kepribadian, pengaruh sosial dan kepuasan konsumen.

\section{REFERENSI}

Amron, A. (2018). The Influence of Brand Image, Design, Feature, and Price on Purchasing Decision of Apple iOS Smartphone in Surakarta, Indonesia. The International Journal of Social Sciences and Humanities Invention, 5(12), 5187-5191.

Baruk, A. I., \& Iwanicka, A. (2015). Polish final purchasers' expectations towards the features of dairy product packaging in the context of buying decisions. British Food Journal.

Beneke, J., Flynn, R., Greig, T., \& Mukaiwa, M. (2013). The influence of perceived product quality, relative price and risk on customer value and willingness to buy: a study of private label merchandise. Journal of Product \& Brand Management.

Blackwell, R. D., Miniard, P. W., \& Engel, J. F. (2007). Consumer behavior (10thed.). Kundi Haryana, India: Thomas South-Western

Bues, M., Steiner, M., Stafflage, M., \& Krafft, M. (2017). How mobile in-store advertising influences purchase intention: Value drivers and mediating effects from a consumer perspective. Psychology \& Marketing, 34(2), 157-174.

Daryanto. (2013). Sari Kuliah Manajemen Pemasaran. Cetakan II.Januari 2013. PT. Sarana Tutorial Nurani Sejahtera. Bandung.

Djatmiko, T., \& Pradanab, R. (2016). Brand image and product price; Its impact for Samsung smartphone purchasing decision. Procedia-Social and Behavioral Sciences, 219, 221-227.

Hendryadi, Tricahyadinata, I., \& Zannati, R (2019). Metode Penelitian: Pedoman Penelitian Bisnis dan Akademik. Jakarta: Lembaga Pengembangan Manajemen dan Publikasi Imperium

Irfan, M., \& Rachmawati, I. (2018). The Influence Of Brand Image And Product Price Towards Purchase Decision On Xiaomi Smartphone In Indonesia. eProceedings of Management, 5(3).

Kotler \& Armstrong. (2012). Prinsip-prinsip Pemasaran Edisi 13. Jilid 1.Jakarta: Erlangga

Kotler \& Keller (2010) manajemen pemasaran, edisi 13 jilid 1. Jakarta: Erlangga

Kotler \& Keller (2016). Marketing Management (15th Ed.) London: Pearson Education Limited

Kwon, K. N., Lee, M. H., \& Kwon, Y.J. (2008). The effect of perceived product characteristics on private brand purchases. Journal of Consumer Marketing.

Lay-Yee, K. L., Kok-Siew, H., \& Yin-Fah, B. C. (2013). Factors affecting smartphone purchase decision among Malaysian generation Y. International Journal of Asian Social Science, 3(12) , 2426-2440. 
Nguyen, A., \& Meng, J. G. (2016). How source of funds affects buyer's judgments of price fairness and subsequent response. Journal of Product \& Brand Management.

Oulasvirta, A., Wahlström, M., \& Ericsson, K. A. (2011). What does it mean to be good at using a mobile device? An investigation of three levels of experience and skill. International journal of human-computer studies, 69(3), 155-169.

Qun, C. J., Howe, L. J., Thai, L. C., \& Kheng, L. W. (2012). Exploring The Factors Affecting Purchase Intention of Smartphone: A Study of Young Adults in Universiti Tunku Abdul Rahman.

Rahim, A., Safin, S. Z, Kheng, L. K., Abas, N., \& Ali, S. M. (2016). Factors influencing purchasing intention of smartphone among university students. Procedia Economics and Finance, 37, 245253.

Russell, J., (2012). Android dominates Southeast Asia's smartphone market: Report [Online]. Available from http:// thenextweb.com/asia/ 2012/09/04/android-southeast-asia-ericssonreport/

Rumate, G. P. (2014). The Impact of Social Influence and Product Quality Attributes to Customer Buying Decision of Iphone in Manado. Jurnal EMBA: Jurnal Riset Ekonomi, Manajemen, Bisnis dan Akuntansi, 2(3).

Shabrin, N., Khandaker, S., Kashem, S. B. A., Hie, C. K., \& Susila, T. (2017). Factors affecting smartphone purchase decisions of generation-Y. Journal of Contemporary Issues in Business and Government, The, 23(1), 47.

Tjiptono, F. (2014). Strategi pemasaran, edisi 2. Yogyakarta: Andi Offset.

\section{PROFIL PENULIS}

Ermalina adalah dosen prodi Manajemen di STIE Ahmad Dahlan. Penulis memiliki ketertarikan pada penelitian di bidang pemasaran, pemasaran strategic, dan perilaku konsumen. Penulis dapat dihubungi pada email: ermalina1962@gmail.com 
Jurnal Manajemen Strategi dan Aplikasi Bisnis, 3(1), 13-20

Ermalina. Harga, Fitur Produk, Keputusan Pembelian

This page intention to blank... 